\title{
Preparation of Chromium (III) Phthalate via Chromium (VI) Oxide using tertiary amyl alcohol as a solvent
}

\author{
MANOJ KUMAR MISHRA \\ Department of Chemistry, BIT Sindri, Dhanbad, India. \\ *Corresponding author E-mail: mkmishrabit@gmail.com \\ http://dx.doi.org/10.13005/ojc/330338 \\ (Received: February 27, 2017; Accepted: April 03, 2017)

\begin{abstract}
Complexes $\left[\mathrm{CrO}_{2}\left(\mathrm{C}_{8} \mathrm{H}_{5} \mathrm{O}_{4}\right)\left(\mathrm{H}_{2} \mathrm{O}\right)_{3}\right]$ and $\left[\mathrm{CrO}_{2}\left(\mathrm{C}_{8} \mathrm{H}_{5} \mathrm{O}_{4}\right)\left(\mathrm{H}_{2} \mathrm{O}\right)_{3}\right] . \mathrm{H}_{2} \mathrm{O}$ were prepared by reduction of $\mathrm{CrO}_{3}$ at room temperature by ethanol in the presence of phthalic acid $\left(\mathrm{H}_{2}\right.$ pht) yield solution that contains monomeric and dimeric $\mathrm{Cr}$ (III) complexes. A solution $\mathrm{H}_{2}$ pht/Cr molar ratio of $1: 1$ and $1: 2$ is indefinitely stable towards precipitation. Their analysis were done by using elemental (C and H), ICP-OES (for Cr \%), UV-Vis, FTIR, ${ }^{1} \mathrm{HNMR}$ and Fast Atomic Bombardment (FAB) Mass spectrometry, where as thermal behaviour was investigated by DSC.
\end{abstract}

Keywords: Chromium (III), tertiary amyl alcohol, thermal behaviour

\section{INTRODUCTION}

Chromium is present everywhere and can be found in three forms; metal ore, trivalent chromium (III) and hexavalent $\mathrm{Cr}$ (VI). The trivalent forms occur naturally in many fresh vegetables and fruits, meat, grains and yeast. Recently insoluble, it is the prevalent form in surface soils where oxidation processes which covert chromium from the hexavalent to trivalent form are most common. Hexavalent chromium also occurs naturally, notably in water saturated (reducing) conditions and it is an indicator of human pollution. This form is relatively soluble and can move readily through soil to groundwater. ${ }^{1-3}$
Complexes which undergo ligand replacement within 1 minute at $25^{\circ} \mathrm{C}$ and $0.1 \mathrm{M}$ reactant concentration are arbitrary termed labile; other less reactive complexes are referred to as inert and also suggested the inert/labile classification of metal complexes with respect to their kinetic stability. The lability of the complexes is dependent upon the activation energy while instability is decided by difference between the free energies of the reactants and the products ${ }^{4-5}$.

In the formation reaction involving replacement of aqua ligands bound to chromium (III) the lability of $\mathrm{Cr}-\mathrm{OH}_{2}$ bond is also very susceptible to the nature of the ligands bound to chromium 
(III) substrate, a behaviour typical of complexes with other metal ion as well. This is particularly true for ligand like biguide, aminopolycarboxylates, quadridentate Schiff bases porphyrineetc bound to chromium (III) ${ }^{6-7}$

\section{Preparation of complexes}

A solution of different molar concentration of $\mathrm{CrO}_{3}$ (dissolved in tertiary amyl alcohol (TAA), mixed with ethanolic solution with different molar concentration of phthalic acid. The resulting solution was left standing in a closed flask at room temperature. After $24 \mathrm{~h}$. precipitation began to separate from solution. The process continued for 5 days, after which time no further precipitation was observed. The stable suspension was filtered, and solid was washed with ethanol and TAA and dried in air.

\section{Characterization of metal complexes Elemental analysis (C\&H)}

Elemental analysis $(\mathrm{C} \& \mathrm{H})$ done at Sophisticated Analytical Instrument Facility (SAIF), Central Drug Research Institute, Lucknow, India.

Inductively coupled plasma optical emission spectroscopy (ICP-OES)

ICP-OES were recorded on Perkin Elmer 5300 DV (Dual view), diluted in acids, Plasma of Argon is the source, at Sophisticated Analytical Instrument Facility (SAIF), Indian Institute of Technology, Madras, India.

\section{UV-vis Spectrophotometry}

UV-vis Spectra recorded on ECIL, Hyderabad, Double beam Spectrophotometer UV5704SS, in the range $200-650 \mathrm{~nm}$ in the
Department of Applied Chemistry, Indian School of Mines, Dhanbad, India.

\section{Fourier Transform Infrared Spectrophotometry (FTIR)}

The infrared spectra of solid samples were recorded in $\mathrm{KBr}$ pellets in the region $4000-400 \mathrm{~cm}^{-1}$ on Perkin Elmer spectrum-2000, Fourier Transform Infrared (FTIR) spectrometer in auto mode in the Department of Applied Chemistry, Indian School of Mines, Dhanbad, India.

\section{Proton Nuclear Magnetic Resonance( $\left.{ }^{1} \mathrm{HNMR}\right)$ spectrometry}

The ${ }^{1} \mathrm{HNMR}$ spectra of complexes were recorded on Bruker DRX-300 instruments in DMSO using Tetramethylsilane (TMS) as an internal standard at Sophisticated Analytical Instrument Facility (SAIF) and Central Drug Research Institute, Lucknow, India.

\section{Fast Atomic Bombardment (FAB) Mass spectroscopy}

The FAB spectra were recorded on Jeol SX-102 (FAB) mass spectrometer instruments at Sophisticated Analytical Instrument Facility (SAIF), Central Drug Research Institute, Lucknow, India.

\section{Differential Scanning Calorimetry (DSC)}

DSC of chromium complexes, was carried out on the Perkin Elmer's DSC-7 at Department of Applied Chemistry, Indian School of Mines University, Dhanbad, India In each case the following methods was used:

Sample pan: Aluminium (perforated); Scan rate: $50^{\circ} \mathrm{C} / \mathrm{Min}$; Start temperature: $50^{\circ} \mathrm{C}$

Table1: Details of samples and their identification

\begin{tabular}{|c|c|c|c|c|c|}
\hline SampleID & $\begin{array}{l}\mathrm{CrO}_{3} \text { :Organic acid: } \\
\text { Solvent (Molar ratio) }\end{array}$ & \multicolumn{2}{|c|}{$\begin{array}{l}\mathrm{CrO}_{3} \text { :Organic } \\
\text { acid (in gram) }\end{array}$} & Colour & Yield \\
\hline PT1 & $\mathrm{CrO}_{3}: \mathrm{H}_{2}$ pht: TAA(1:1) & \multicolumn{2}{|c|}{$1: 1.66$} & Blue- green & $1.38 \mathrm{~g} ; 53 \%$ \\
\hline PT2 & $\mathrm{CrO}_{3}: \mathrm{H}_{2}$ pht:TAA(1:2) & \multicolumn{2}{|c|}{$1: 3.23$} & Bule-green & $2.59 \mathrm{~g}, 60 \%$ \\
\hline \multicolumn{6}{|c|}{ Table 2: Elemental(C\&H) and ICP-OES analytical data of metal complexes } \\
\hline \multirow[t]{2}{*}{ Sample Id } & \multicolumn{3}{|c|}{ Found (Calculated) (\%) } & \multicolumn{2}{|c|}{ Molecular formula } \\
\hline & C & $\mathbf{H}$ & & $\mathrm{Cr}$ & \\
\hline \multirow{2}{*}{$\begin{array}{l}\text { PT } 1 \\
\text { PT } 2\end{array}$} & $32.88(31.68)$ & $3.89(3.63)$ & 16.95 & $(17.16)$ & $\mathrm{C}_{8} \mathrm{H}_{11} \mathrm{CrO}_{9}$ \\
\hline & $31.21(29.91)$ & $3.70(4.05)$ & & $(16.20)$ & $\mathrm{C}_{8} \mathrm{H}_{13} \mathrm{CrO}_{10}$ \\
\hline
\end{tabular}


End temperature: $450^{\circ} \mathrm{C}$; Purge gas: Nitrogen (at the rate of $20 \mathrm{ml} / \mathrm{min}$ at the exist)

The following Perkin Elmer's DSC software was used for the purpose: Standard (Version 2.1 \& 3.1); Kinetics (3.1); Auto mode (3.1); The DSC was calibrated using indium and zinc as standard.

\section{Elemental(C\&H \%) and ICP-OES (Cr \%) Analysis of complexes}

Elemental (C\&H) and ICP-OES (Cr) analytical data of metal complexes are shown in Table 2. The complexes formed were brightly colored and were insoluble in water and in common organic solvents, but was found to be soluble in DMSO at room temperature. It was observed that as the molar ratio of $\mathrm{Cr}$ : acidincreased the number of coordinating Hpht ligands in the complexes increased proportionally.

\section{UV-VIS spectrometry studies}

The UV-VIS studies of chromium complexes and their consolidated values of the peaks (along with absorbance) of these spectra are given in Table 3.

It was reported ${ }^{8}$ that the electronic spectrum for solution prepared by dissolving active $\mathrm{Cr}$ (III)-hydroxide in ethanolic solution of $\mathrm{H}_{2}$ pht has absorption maxima at 587 and $436 \mathrm{~nm}$. The two maxima lie in the region of the ${ }^{4} \mathrm{~A}_{2 \mathrm{~g}} \rightarrow{ }^{4} \mathrm{~T}_{1 \mathrm{~g}}$ and ${ }^{4} \mathrm{~A}_{2 g} \rightarrow{ }^{4} \mathrm{~T}_{2 g}$ d-d transitions of octahedral chromium complexes. It was also suggested that these solutions contain a mixture of low oligomeric $\mathrm{Cr}$ (III) complexes in the form of ions and ionic associates.

UV-visible spectra of both the complexes present two bands in the ranges of 467-500 and $525 \mathrm{~nm}$ which can be assigned respectively to ${ }^{4} \mathrm{~A}_{2 g} \rightarrow{ }^{4} \mathrm{~T}_{19}$ and ${ }^{4} \mathrm{~A}_{2 g} \rightarrow{ }^{4} \mathrm{~T}_{2 \mathrm{~g}} \mathrm{~d}$-d transitions of octahedral chromium complexes.

In the case of $\mathrm{Cr} /$ phthalic acid solutions $\left(\mathrm{Cr} / \mathrm{H}_{2}\right.$ pht $)$ the bands observed at 495 and $553 \mathrm{~nm}$ of chromium in aqueous solution are characteristic of oligomeric species, probably the monomeric complexes.

\section{FTIR studies of $\mathrm{Cr} / \mathrm{H}_{2}$ pht complexes}

The FTIR of $\mathrm{Cr} / \mathrm{H} 2 \mathrm{pht}$ complexes and their assignments are given in Table 4.

PT1: Infrared $\left(\mathrm{Cm}^{-1}\right): 3399,1695,1551$, $1415,1152,1039,755,703,656,538,376$

PT2: Infrared $\left(\mathrm{Cm}^{-1}\right): 3071,1697,1554$, 1492, 1412, 1283, 1154, 1072, 797, 750, 712,536

The characteristic absorption peak at $1686 \mathrm{~cm}^{-1}$ and $1281 \mathrm{~cm}^{-1}$ may be attributed to $\mathrm{C}=\mathrm{O}$ of and $\mathrm{C}-\mathrm{O}$ stretching frequency of carboxyl group of phthalic acid respectively. The absorption peaks at $1403,1452,1466,1497$ and $1586 \mathrm{~cm}^{-1}$ are probably due to the $v(-\mathrm{COO})$ stretching frequency of carboxyl group of phthalic acid. The absorption of $\mathrm{O}-\mathrm{H}$ stretching of one carboxyl group appeared

Table 3: UV-VIS spectral data of chromium complexes in DMSO

\begin{tabular}{|c|c|c|c|c|c|c|}
\hline \multicolumn{2}{|c|}{ Sample ID } & \multicolumn{4}{|c|}{$\lambda_{\max } \mathrm{nm}(\log \varepsilon)$} & \\
\hline PT1 & \multirow{3}{*}{\multicolumn{6}{|c|}{$\begin{array}{l}552.5(2.485), 495(2.395), 503.0(2.090), 520.5(1.801), 525.5(1.795), \\
512.0(1.787), 467.5(1.408), 587.5(1.405), 459.0(1.382), 420.5(0.994) \\
615.5(1.734), 603.5(1.687), 625.5(1.665), 633.0(1.653), 640.5(1.651), \\
646.0(1.624), 553.5(1.622), 495.0(1.496), 519.5(1.305), 509.5(1.264)\end{array}$}} \\
\hline \multirow[t]{2}{*}{ PT2 } & & & & & & \\
\hline & & & & & & \\
\hline \multicolumn{7}{|c|}{ Table 4: FTIR spectral data of $\mathrm{Cr} / \mathrm{H}_{2}$ pht complexes and their assignment in $\mathrm{cm}^{-1}$} \\
\hline Sample Id & $v(\mathbf{C}=\mathbf{0})$ & $v(\mathbf{C O})$ & $v(-\mathrm{CoO})$ & $v(\mathbf{C r}-\mathbf{O})$ & $\begin{array}{l}v(\mathrm{O}-\mathrm{H}) \text { of } \\
-\mathrm{COOH}\end{array}$ & $\begin{array}{r}\delta(\mathrm{OC}=0) \\
+v(\mathrm{Cr}-\mathrm{O})\end{array}$ \\
\hline PT1 & 1695 & 1283 & 1415,1551 & 656,538 & 3399 & 755 \\
\hline PT2 & 1697 & 1283 & $1412,1492,1554$ & 650,536 & 3071 & 797 \\
\hline
\end{tabular}


as a sharp band at $3697 \mathrm{~cm}^{-1}$. The absorption of $\mathrm{O}-\mathrm{H}$ stretching of second carboxyl group appeared as a broad band near $3007 \mathrm{~cm}^{-1}-2525 \mathrm{~cm}^{-1}$. The absorption peak at $2888 \mathrm{~cm}^{-1}$ and $2651 \mathrm{~cm}^{-1}$ was due to the $\mathrm{C}-\mathrm{H}$ stretching (superimposed upon $\mathrm{O}-\mathrm{H}$ stretching). The sharp absorption peak at $740 \mathrm{~cm}^{-1}$ indicates the ortho-disubstitution in the phthalic acid, other vibrational frequency at $3007 \mathrm{~cm}^{-1}$ and $1686 \mathrm{~cm}^{-1}$ are assigned to $v(\mathrm{C}-\mathrm{H}) \& v(\mathrm{C}=\mathrm{C})$ of aromatic ring respectively.

In the IR spectrum of the complexes the band at $1695-1697 \mathrm{~cm}^{-1}$ are attributed to $\mathrm{C}=\mathrm{O}$ stretching of complexes ${ }^{9}$. The absorption bands in the range $1283 \mathrm{~cm}^{-1}$ is attributed to $\mathrm{C}-\mathrm{O}$ of carboxyl group. The symmetric and asymmetric stretching vibrations of $\mathrm{COO}^{-}$group are observed at $1551-1554 \mathrm{~cm}^{-1}$ as a shoulder and $1412-1492 \mathrm{~cm}^{-1}$ as a strong peak respectively, The sharp absorption band of the phthalic acid due to $\mathrm{O}-\mathrm{H}$ of the one carboxyl group in the range $3697 \mathrm{~cm}^{-1}$ disappears in the complexes and new bands appears in the range 3071-3399 $\mathrm{cm}^{-1}$ due to the intermolecular hydrogen bonded $v(\mathrm{O}-\mathrm{H})$ of the carboxyl group. Disappearance of the absorption bands of the phthalic acid due to $\mathrm{O}-\mathrm{H}$ of the second carboxyl group in the range $3007-2525 \mathrm{~cm}^{-1}$ in the complexes indicates the deprotonation of the one acidic group of the ligand and appearance of new bands in the region $536-650 \mathrm{~cm}^{-1}$ in the spectra of complexes are attributed to $v(\mathrm{Cr}-\mathrm{O})$ as seen in the spectra of metal complexes suggest the coordination of the oxygen atoms to the metal ion and indicate that the product has been formed ${ }^{10}$. $\mathrm{Cr} /$ phthalic acid-TAA ( $\mathrm{Cr} / \mathrm{H}_{2}$ pht-TAA) complexes PT1 and PT2 show bands in the $1039-1072 \mathrm{~cm}^{-1}$ region that can be assigned to $\mathrm{Cr}-\mathrm{O}$ vibrations ${ }^{11-12}$. Strong and medium bands appear in this region of the spectrum of the $\mathrm{Cr} /$ phthalic acid-TAA $\left(\mathrm{Cr} / \mathrm{H}_{2}\right.$ pht-TAA) complexes.

\section{${ }^{1} \mathrm{HNMR}$ studies of $\mathrm{Cr} / \mathrm{H}_{2}$ pht complexes}

Proton resonance spectral data of $\mathrm{Cr} /$ $\mathrm{H} 2$ pht complexes and their assignments are given in Table5.

Experimental results for the complexes show that the peaks of protons belonging to different groups were very broad and could not be distinguished .The ${ }^{1} \mathrm{H}$ NMR spectra of complexes slightly changed compared to those of the corresponding ligand. The aromatic ring protons show peak at 6.64-7.88 ppm and a comparison of this spectrum with the spectrum

Table 5: ${ }^{1} \mathrm{HNMR}$ spectral data of $\mathrm{Cr} / \mathrm{H}_{2}$ pht complexes and their assignment in $\delta$

\begin{tabular}{lll}
\hline Complexes & Chemical Shift & Assignment \\
\hline PT1 & $3.32,2.50,1.23$, & $3.32(-\mathrm{OH}), 2.50$ (Protio-solvent component) \\
& $1.15,1.04,0.86,0.82$ & \\
PT2 & $7.84,7.56,6.64,3.47,2.50,1.74$, & $6.64-7.84(4 \mathrm{H}, \mathrm{ArH}), 3.47(-\mathrm{OH})$ \\
& 1.35, & $2.50(\mathrm{Protio}-\mathrm{solvent}$ component) \\
& $1.24,1.04,0.82$ & $0.82-1.24$ (may be due to \\
& & the $-\mathrm{CH}_{2}$ group of amyl group) \\
\hline
\end{tabular}

Table6: FAB mass data of complex PT1

\begin{tabular}{lcc}
\hline $\begin{array}{l}\text { Peak } \\
\text { position }\end{array}$ & $\begin{array}{c}\text { Expected } \\
\text { fragmentation } \\
\text { species }\end{array}$ & $\begin{array}{c}\text { Calculated } \\
\text { mass }\end{array}$ \\
\hline 307 & $\mathrm{CrO}_{2}\left(\mathrm{C}_{8} \mathrm{H}_{5} \mathrm{O}_{4}\right)\left(\mathrm{H}_{2} \mathrm{O}\right)_{3}$ & 303 \\
289 & $\mathrm{CrO}_{(}\left(\mathrm{C}_{8} \mathrm{H}_{5} \mathrm{O}_{4}\right)\left(\mathrm{H}_{2} \mathrm{O}\right)_{3}$ & 287 \\
273 & $\mathrm{Cr}\left(\mathrm{C}_{8} \mathrm{H}_{5} \mathrm{O}_{4}\right)\left(\mathrm{H}_{2} \mathrm{O}\right)_{3}$ & 271 \\
216 & $\mathrm{Cr}\left(\mathrm{C}_{8} \mathrm{H}_{5} \mathrm{O}_{4}\right)$ & 217 \\
165 & $\left(\mathrm{C}_{8} \mathrm{H}_{5} \mathrm{O}_{4}\right)$ & 165 \\
137 & $\left(\mathrm{C}_{7} \mathrm{H}_{5} \mathrm{O}_{3}\right)$ & 137 \\
\hline
\end{tabular}

of the free ligand confirmed a downfield shift due to coordination. The ${ }^{1} \mathrm{H}$ NMR spectrum of the complex MRPT1 showed resonance at $3.32 \mathrm{ppm}$, which may be for the presence of $-\mathrm{OH}$ of the complex. Similarly the ${ }^{1} \mathrm{H}$ NMR spectrum of the complex MRPT2showed resonances at 3.47 ppm and 0.82-1.24 ppm, which may be for the presence of proton of $-\mathrm{OH}$ of the complex and methylene protons of $-\mathrm{CH}_{2}$ of the amyl group respectively. The complexes show resonances at $2.50 \mathrm{ppm}$, which may be for the presence of protiosolvent component ${ }^{13}$. 
Table7: FAB mass data of complex PT2

\begin{tabular}{lcc}
\hline $\begin{array}{c}\text { Peak } \\
\text { position }\end{array}$ & $\begin{array}{c}\text { Expected } \\
\text { fragmentation } \\
\text { species }\end{array}$ & $\begin{array}{c}\text { Calculated } \\
\text { mass }\end{array}$ \\
\hline 320 & $\mathrm{CrO}_{2}\left(\mathrm{C}_{8} \mathrm{H}_{5} \mathrm{O}_{4}\right)\left(\mathrm{H}_{2} \mathrm{O}\right)_{4}$ & 321 \\
307 & $\mathrm{CrO}_{(}\left(\mathrm{C}_{8} \mathrm{H}_{5} \mathrm{O}_{4}\right)\left(\mathrm{H}_{2} \mathrm{O}\right)_{4}$ & 305 \\
289 & $\mathrm{CrO}\left(\mathrm{C}_{8} \mathrm{H}_{5} \mathrm{O}_{4}\right)\left(\mathrm{H}_{2} \mathrm{O}\right)_{3}$ & 287 \\
273 & $\mathrm{Cr}\left(\mathrm{C}_{8} \mathrm{H}_{5} \mathrm{O}_{4}\right)\left(\mathrm{H}_{2} \mathrm{O}\right)_{3}$ & 271 \\
216 & $\mathrm{Cr}\left(\mathrm{C}_{8} \mathrm{H}_{5} \mathrm{O}_{4}\right)$ & 217 \\
167 & $\left(\mathrm{C}_{8} \mathrm{H}_{5} \mathrm{O}_{4}\right)$ & 165 \\
136 & $\left(\mathrm{C}_{7} \mathrm{H}_{5} \mathrm{O}_{3}\right)$ & 137 \\
107 & $\left(\mathrm{C}_{7} \mathrm{H}_{5} \mathrm{O}\right)$ & 105 \\
89 & $\left(\mathrm{C}_{7} \mathrm{H}_{5}\right)$ & 89 \\
79 & $\left(\mathrm{C}_{6} \mathrm{H}_{5}\right)$ & 77 \\
\hline
\end{tabular}

Calculated mol. Wt. of the complex: 321; Observed molecular Ion Peak (m/z): 320

\section{DSC studies of $\mathrm{Cr} / \mathrm{H}_{2}$ pht complexes:}

DSC themogarm of $\mathrm{Cr} / \mathrm{H} 2 \mathrm{pht}$ complexes and their kinetic parameter are given in table 8 .

\section{$\mathrm{Cr} / \mathrm{H}_{2}$ pht complexes}

Changes in the kinetic parametersenthalpy $(\Delta H)$, activation energy $(E a)$, InK , ordrer of reaction $(n)$ and peak temperature of the $\mathrm{Cr} /$ acid complexes are observed from DSC thermogram. In both the cases reaction with a exothermic heat flow took place at 226.98 and $403.98^{\circ} \mathrm{C}$. The second step decomposition was found to be an exothermic process, having high value of activation energy. The

Table 8: Kinetic parameters of $\mathrm{Cr} / \mathrm{H}_{2}$ pht complexes obtained from DSC thermogram

\begin{tabular}{|c|c|c|c|c|c|c|}
\hline $\begin{array}{l}\text { Sample } \\
\text { code }\end{array}$ & $\begin{array}{c}\text { Temperature } \\
\text { range }\left({ }^{\circ} \mathrm{C}\right)\end{array}$ & $\begin{array}{c}\text { Peak } \\
\text { temp. } \\
\left({ }^{\circ} \mathrm{C}\right)\end{array}$ & $\ln k_{0}$ & $\begin{array}{l}\text { Change in } \\
\text { enthalpy } \\
\text { (DH)(J/g) }\end{array}$ & $\begin{array}{c}\text { Activation } \\
\text { energy(Ea) } \\
\text { (KJ/mol) }\end{array}$ & $\begin{array}{l}\text { order of } \\
\text { reaction }\end{array}$ \\
\hline PT1A & $70.68-175.67$ & 118.05 & $17.53 \pm 0.37$ & 175.21 & $69.4 \pm 1.49$ & $1.41 \pm 0.03$ \\
\hline PT1B & 180.88-330.85 & 226.98 & $1.33 \pm 0.02$ & -66.82 & $26.77 \pm 0.57$ & $0.7 \pm 0.01$ \\
\hline PT2A & 67.4-183.55 & 114.75 & $15.87 \pm 0.34$ & 105.44 & $63.85 \pm 1.37$ & $1.5 \pm 0.03$ \\
\hline РT2B & $345.44-428.07$ & 403.38 & $34.17 \pm 0.73$ & -18.69 & $210.38 \pm 4.54$ & $1 \pm 0.02$ \\
\hline
\end{tabular}

\section{FAB Mass of $\mathrm{Cr} / \mathrm{H}_{2}$ pht complexes}

Results from the FAB mass analysis were inferred on the basis as followed by Barnwal et al., [14].The FAB Mass of $\mathrm{Cr} / \mathrm{H} 2$ pht complexes and their expected fragmentation species are given in Table6-7.

PT 1: $\left[\mathrm{CrO}_{2}\left(\mathrm{C}_{8} \mathrm{H}_{5} \mathrm{O}_{4}\right)\left(\mathrm{H}_{2} \mathrm{O}\right)_{3}\right]$

Anal.: found $\mathrm{C}, 32.88 ; \mathrm{H}, 3.89 ; \mathrm{Cr}$, 16.95Calcd. For $\mathrm{C}_{8} \mathrm{H}_{11} \mathrm{CrO}_{9}: \mathrm{C}, 31.68 ; \mathrm{H}, 3.63$; $\mathrm{Cr}$, 17.16

Calculated mol. wt. of the complex: 303; Observed molecular Ion Peak (m/z): 307

The difference in molecular weight may correspond to the association of $4 \mathrm{H}^{+}$fragmentation

PT 2: $\left[\mathrm{CrO}_{2}\left(\mathrm{C}_{8} \mathrm{H}_{5} \mathrm{O}_{4}\right)\left(\mathrm{H}_{2} \mathrm{O}\right)_{3}\right] \cdot \mathrm{H}_{2} \mathrm{O}$

Anal.: found $\mathrm{C}, 31.21 ; \mathrm{H}, 3.70 ; \mathrm{Cr}$, 15.08Calcd. For $\mathrm{C}_{8} \mathrm{H}_{13} \mathrm{Cr} \mathrm{O}_{10}: \mathrm{C}, 29.91 ; \mathrm{H}, 4.05 ; \mathrm{Cr}$, 16.20 decomposition followed first and second order of reaction. The complexes showed an endothermic peak between 70.68 to $183.55^{\circ} \mathrm{C}$ for dehydration process ${ }^{15}$. First step decomposition is associated with endothermic process while generally second is associated with exothermic process. The final step change of $\mathrm{Cr} / \mathrm{H}_{2}$ pht complexes (oligomeric in nature) could not be recorded as scanning was done upto $450 \stackrel{\circ}{\mathrm{C}}$.

\section{CONCLUSION}

When $\mathrm{CrO}_{3}$ dissolved in tertiary amyl alcohol (TAA) is mixed at room temperature with an ethanolic solution of phthalic acid, reduction of chromium (VI) by ethanol takes place yielding solutions of chromium (III). Results showed that the complexes formed were probably monomeric. It was noted that changing the reaction condition, only slowed down the reaction, rate of formation of complexes, not the nature of products. The UV-Vis spectral analysis of complexes indicated formation 
of octahedral chromium complexes. FTIR spectra of the complexes formed indicated presence of Co-ordinated water molecules in the complexes. Deprotonation of one acidic group of the ligand is shown by FTIR as well as NMR spectrometry while appearance of new bands in the FTIR spectra of complexes suggested co-ordination of oxygen atoms to the metal ions and indicated formation of new compound. From the FAB mass spectrometry molecular formula of the complexes formed could be predicted. The kinetics and the lability of complexes could be predicted from the DSC. DSC studies indicated that the $\mathrm{Cr} / \mathrm{H}_{2}$ pht complexes may be stable at the ambient temperature, may be labile at higher temperature.

\section{REFERENCES}

1. Lin,J.T; Hagen, G.P; Ellis,J.E. Organometallic, 1984, 3, 1288

2. Bakac,A.; Espenson, J.H. Inorg. Chem., 1992,31,1108

3. Wilkinson, G. Polyhedron, 1993, 12, 363

4. Taube, H. Chem.Rev., 1952,50,59

5. Lay,P.A.; Levina, A. J.Am. Chem.Soc., 1998, 120,6704

6. Ramasami,T.; Sykes, A.G. Inorg.Chem. 1973, 15, 2645

7. Banerjea,D.;Chakravarti,B.Inorganic ChimicaActa,1995, 240, 117-123

8. Vasovic,D.;Stojakovic, D.J. J.Coord.Chem., 1988, 17,325

9. Hewkin, D.J.; Griffith, W.P. J.Chem Soc., 1966,

\section{A, 472-475}

10. L.J.Bellamy, The Infrared Spectrum of complex molecules, Third ed. Chapman and Hall LtdLondon, 1975

11. Trapkovska,M.; Soptrajanov, B.; Pejov,L. J.Mol. Struct.,2003, 654, 21-26

12. Soptrajanov, B.; Trpkovska, M. J.Mol. Struct.,1992,267,185

13. Broadhurst, C.L.; Schmidt, W.F.; Reeves, J.B.; Polansky,M.M.; Gautschi,K. ; Anderson, R.A. J.Inorg.Biochem., 1997,66, 119

14. Baranwal, B.P.; Fatma, T. Journal of Molecular Structure, 2005, 750, 75

15. Deb, N.;Baruah, S.D.;Dass, N.N. Thermochim. Acta, 1996,285,301 